\title{
EFECTOS Y NATURALEZA DEL SALARIO MÍNIMO*
}

\author{
Jorge RamÓn Martínez Rivera* \\ Universidad de Chile
}

\begin{abstract}
RESUMEN: En este trabajo se presenta una perspectiva evolutiva (histórica) y otra teórica sobre el salario mínimo, contextualizando el problema de la fijación legislativa de las retribuciones del trabajo dentro de otro más general, el de la fijación forzosa de los precios. Se exponen y refutan las teorías más comunes para defender los salarios mínimos, para luego presentar la naturaleza de éste, vale decir, su expresión jurídica más simple. Finalmente, se concluye que el intervencionismo legislativo es incapaz de alterar las leyes económicas que regulan la formación de los precios, y que sólo empeora la situación de los trabajadores, además de resultar incompatible con los principios del Estado de Derecho, al promover la desigualdad.
\end{abstract}

Palabras clave: Salario mínimo, fijación de precios, economía del trabajo, desempleo institucional

ABSTRACT: In this work, we present an evolutionary (historical) perspective, and a theoretical one, on the minimum wage, contextualizing the issue of the legislative establishment of remuneration of labor in a more general one, which is the forced pricing. We present and refute the most common theories to defend the minimum wage, and then present the nature of it, i.e., its simplest legal expression. Finally, we conclude that the legislative intervention is unable to alter the economic laws that govern the formation of prices, and that only makes things worse for the situation of workers, in addition to be incompatible with the principles of the Rule of law, because it promotes inequality.

Key words: minimum wage, forced pricing, labor economics, institutional unemployment

\section{EL PROBLEMA}

Resulta curioso que la norma del art. 42 del Código del Trabajo (CT) que reza: "El sueldo no podrá ser inferior a un ingreso mínimo mensual", haya convertido un problema esencialmente económico en otro político. Este enfoque errado se basa en la suposición de que sin intervención estatal los trabajadores estarían entregados a la explotación patronal y a la "ley de la selva" del mercado.

Ciertamente que tal posición no es científicamente admisible, y se funda en el desconocimiento del método propio para abordar este tipo de problemas, vale decir, distinguir entre la cuestión teórica y la político-social.

Se omite en el debate público y académico, que los salarios, como precios que son, están sujetos a unas leyes económicas abstractas y cognoscibles, y que su manipulación tiene unos efectos inexorables que quedan ocultos a los ojos de quienes desconocen el proceso llamado "mercado". Asimismo, como se verá, la manipulación de las regularidades económicas, a través de la legislación, no ha sido una vía eficaz para conseguir los fines bienintencionados que los interventores se han propuesto. En este sentido, podemos afirmar que la actividad del Estado, aun con su inmenso poder, resulta impotente para alterar las leyes económicas de la distribución del ingreso entre los diversos factores de producción, a saber: renta de la tierra, salarios del trabajo e interés del capital ${ }^{1}$.

Este trabajo es un extracto de una obra teórica mayor intitulada "Estudios de Economía y Legislación Laboral". Abogado, Ayudante del Departamento de Derecho del Trabajo y de la Seguridad Social de la Universidad de Chile, Becario del Magíster en Derecho del Trabajo y de la Seguridad Social de la Universidad de Chile. 
Por lo mismo, el debate debe reorientarse a considerar cuáles son los efectos reales de la fijación legislativa del piso de retribución por los servicios del trabajo como paso previo a la implementación de cualquier política pública sobre salarios mínimos o-como se dice hoy en día- de una "nueva institucionalidad" para éste; en otras palabras, antes que la pregunta sobre "¿cuál ha de ser el monto del salario mínimo?” se debe responder una que es previa: “¿debe existir tal cosa como un salario mínimo?".

En las páginas siguientes se presenta una visión amplia del salario mínimo, que contextualiza el problema dentro de otro más general: el de la manipulación de los precios. A continuación, se realiza el análisis propiamente económico, en que se refutan algunas falacias comunes en el plano teórico para justificar la existencia de salarios mínimos legales; por último, se aborda la categorización jurídica del salario mínimo, enunciando sus efectos sobre las libertades que debe garantizar el Estado de Derecho.

\section{HISTORIA Y TEORÍA}

La falta de abstracción teórica por parte de los observadores de fenómenos naturales o sociales, ha sido enemiga del avance científico en todas las áreas del conocimiento. Tal como en la Historia de la Biología, a partir de la observación de las moscas que aparecían en los restos orgánicos putrefactos, hasta el siglo XVII se creyó en la abiogénesis, esto es, que los insectos se generaban espontáneamente desde la propia materia en descomposición, sin que mediara reproducción de otros individuos de la especie. Pasarían todavía dos siglos más, hasta que Pasteur echara por tierra definitivamente estas construcciones que por milenios -desde Aristóteles- formaron parte del acervo científico de la humanidad ${ }^{2}$. Con las fijaciones coactivas de precios ha ocurrido algo muy similar: la observación epidérmica de los fenómenos sociales de intercambio ha llevado a crear toda una mitología de causas, efectos y pseudo ciencia sobre los intercambios y la forma de manipularlos.

La eterna incomprensión del funcionamiento del sistema de precios (de los que forman parte los salarios), ha permitido que durante la Historia se materializaran diversos planes para controlarlos. En Roma, por ejemplo, una completa política de precios máximos se llevó a cabo para conseguir que la plebe urbana pudiera acceder a los alimentos que el totalitarismo imperial hacía cada vez más escasos y caros. No tardaron los agricultores en detener la producción ante la política de precios máximos llevada adelante por los emperadores, quienes en respuesta prohibieron a los labradores marcharse del campo, adscribiéndolos a la tierra, lo que no brindó alivio alguno a la crisis ${ }^{3}$. Pronto los dueños de la tierra abandonaron su explotación y la encargaron a villanos y libertos que huían de la hambruna de la ciudad. Nacía el régimen de producción servil ${ }^{4}$.

Bates Clark, John. The Distribution of Wealth. Londres, Inglaterra: The MacMillan Company, 1938.

Villee, Claude. Biología. -7º Ed.-. México: Mc Graw Hill, 1988, pp. 8-9.

El colapso del imperio romano fue también el del intervencionismo. Alamiro de Ávila refiere con meridiana claridad los aspectos económicos de la crisis romana del siglo III, y como el dirigismo imperial fue incapaz de solucionarla: "A partir del siglo III la crisis hace decaer el comercio como todas las actividades económicas. Las tentativas intervencionistas de Diocleciano trataron de impedir las alzas de precios, congelándolos, así como también los salarios y adscribiendo a los comerciantes a su oficio, pero sin éxito (...)” "La gran crisis del siglo III hace bajar la producción en general y rompe la unidad económica del mundo romano: se vuelve principalmente en occidente a un sistema económico geográficamente restringido. Los emperadores pretenden superar la crisis con medidas intervencionistas como adscribir, hereditariamente, a los campesinos a la tierra y a los artesanos a los collegia, pero estas medidas resultan del todo contraproducentes y la crisis se mantiene en occidente hasta la desaparición del imperio, con breves períodos de cierta reacción (...)” Ávila, Alamiro de. Derecho Romano. -2 Ed.-. Santiago, Chile: Editorial Jurídica de Chile, 2000, pp. 137 y 139.

4 Mises, Ludwig. La Acción Humana. Tratado de Economía. -8 Ed.-. Madrid, España: Unión Editorial, 2007, p. 908. 
Si una política de precios máximos es usada para "proteger" la demanda, no es difícil concluir que una política contraria, de precios mínimos, se utiliza para "proteger" la oferta. Los precios mínimos que fija la autoridad tienen por finalidad que los vendedores puedan colocar sus mercaderías de forma "conveniente". Al observador superficial y al intervencionista le parecerá esto una cuestión de lo más natural, pues en su aversión a la abstracción, ni siquiera ha llegado a preguntarse por qué los precios son los que son, y si su alteración acarreará o no consecuencias indeseadas 5 .

Sin embargo, la labor del estudioso consiste, precisamente, en poner bajo el crisol de la ciencia las aproximaciones intuitivas de los profanos. Para la teoría económica, como veremos, la fijación de precios máximos sólo conduce a la disminución de la producción; lo que al tratar de remediarse con la dirección coactiva de ésta, acaba con la fijación de los costos (salarios, materias primas, capitales) de la industria intervenida; y el final es siempre el mismo: racionamiento, mercado negro y la instauración de una policía de precios. No más halagüeño es el panorama de los precios mínimos que atraen más oferentes a la producción del bien favorecido, lo que se traduce en un exceso de producción que es imposible de colocar sin pérdidas empresariales, luego la solución intervencionista es subsidiar la producción, vale decir, empobrecer a los contribuyentes para que se siga produciendo en la industria con precios mínimos, o destruir la producción excedente para que se reduzca la presión hacia la baja de los precios. Como se ve, una intervención en el mercado siempre tiene unas consecuencias que escapan al ojo superficial, y al tratar de corregirlas el interventor, por medio de otra intervención, sólo se está avanzando hacia el intervencionismo total, la dictadura.

Pues bien, ¿por qué si rechazamos los controles de precios (como se rechaza la generación espontánea de los insectos o cualquier otra superstición), de buena gana se acepta la fijación coactiva de salarios a través del salario mínimo?

Esta no es una cuestión tan sencilla de contestar, ya que implica desentrañar y refutar una verdadera maraña de errores y motivos emocionales que se superponen unos sobre otros hasta construir un formidable tinglado de supercherías. Pero, para desgracia de los defensores del sueldo mínimo, tratándose de asuntos que se relacionan con la vida práctica, es imposible que su doctrina sea capaz de explicar la realidad sin incurrir en contradicciones lógicas insalvables.

Revisemos el primer pilar del tinglado: aquel eslogan que reza "el trabajo no es una mercancía, ya que "forma parte del trabajador", y por lo tanto no es un bien común y corriente" ${ }^{\text {. Se pre- }}$ senta aquí al empleador cual moderno Shylock, exigiendo con causa del contrato -de trabajo-, su libra de carne humana. Esta caricatura, presente también en $\mathrm{Marx}^{7}$, es el primer acto de la puesta en escena emocional al servicio del intervencionismo en las relaciones de trabajo.

Esta afirmación, sin fundamento científico alguno (que podría haber estado bien para una comedia de Shakespeare), forma parte de la fraseología de todos quienes aspiran a reemplazar las decisiones que se darían en el ámbito de las relaciones laborales no intervenidas, por sus propios caprichos. Este eslogan tuvo fijación jurídica universal cuando se introdujo en los tratados de paz que pusieron fin a la Primera Guerra Mundial (art. $427 \mathrm{~N}^{\circ} 1$ del Tratado de Versalles) de donde nació la Organización Internacional del Trabajo (OIT) ${ }^{8}$; lo que contribuyó a otorgarle una auctoritas de verdad que no merecieron otras partes más importantes de estos tratados. Se puede observar

En nuestra disciplina tales consecuencias, se conocen como "efecto perverso de la norma laboral".

Gamonal, Sergio. Derecho Colectivo del Trabajo. Santiago, Chile: LegalPublishing, 2008, p. 233.

Marx, Karl. El Capital. Vol. I. México: Fondo de Cultura Económica, 2012, p. 228.

La OIT ha desempeńado un crucial papel en la promoción de políticas de sueldos mínimos, así su Convenio 131 (1970) convierte en obligación para los Estados que adhieran a él, legislar salarios mínimos obligatorios. 
que una base necesaria de todo el discurso intervencionista se encuentra en esta "compasiva" y "protectora" declaración.

Obviamente, y a pesar de la superchería, a través del contrato de trabajo no se compra al trabajador, ni una "parte", porción o fracción de él. El trabajador, como sujeto, no es objeto del tráfico jurídico. Ninguna persona sensata asume que al celebrar un contrato de trabajo ha comprometido una parte de sí misma o que ha adquirido tal o cual fracción de la persona del empleado. Afirmar tal cosa es una majadería que no resiste mayor análisis.

Se retrucará que lo que se ha querido decir es que el trabajo, entendido como una prestación de servicios a las órdenes de otro, no es una mercancía susceptible de valoración económica como el resto de las mercaderías. Aunque ése no es el sentido que se desprende del tenor literal de la cita anterior (que dice que el trabajo no es una mercancía porque "forma parte del trabajador"9), parece menos insensato. Sin embargo, lo es mucho más de lo que parece a primera vista.

Lo que el empresario paga a través del salario no es "trabajo" en un sentido abstracto, como pudiera pensarse. Al empresario, que organiza los factores para un determinado proceso productivo, no le interesa un trabajo genérico o a granel, entendido como un esfuerzo físico puesto a su disposición. No, el empresario necesita un cierto tipo de trabajo, a saber: el del electricista, albañil, redactor, vendedor, guardia, etc., según el proceso productivo que esté llevando a cabo. Entonces, ¿qué se remunera cuando se compensa al trabajador? Como lo que mueve a contratar mano de obra es la productividad esperada por el trabajador adicional contratado, lo que se contrata por el empresario es la contribución que realiza este trabajador al proceso productivo ${ }^{10}$ (por lo que el salario está relacionado con los precios que se den en el mercado de bienes de consumo). Y la contribución que realiza el trabajador tiene una naturaleza económica y jurídica muy clara: se trata de bienes y/o servicios, que como tales se transan en el mercado.

\section{ANÁLISIS ECONÓMICO Y JURÍDICO}

Consecuencia de la falacia de que el "salario no es una mercancía" ha surgido un tratamiento para éstos que los pone al margen de lo que en realidad son, "un precio". El precio que se paga por los servicios del trabajo. Los salarios, como precios que son, se rigen por las leyes inderogables de la oferta, la demanda y de la utilidad marginal, por lo que es posible descartar insensateces tales como:

"No existe evidencia empírica de carácter unívoco, es decir en una sola dirección respecto a los efectos del salario mínimo en el desempleo. Existen casos donde no se perciben cambios significativos en la tasa de ocupación frente a un alza en el salario mínimo, mientras que hay otros en que sí habría impacto (negativos, pero también positivos)"11.

Es un hecho irrefutable, que al ser los salarios un precio (digan lo que digan los laboralistas), la Historia -lo empírico- está plagada de evidencias que señalan que los intentos por fijar precios por sobre los de mercado sólo conducen al despilfarro de recursos, a la sobreoferta y a la disminu-

\footnotetext{
Gamonal, Sergio, op. cit. (n. 6), p. 233.

10 Martínez, Jorge. "Teoría Pura de los salarios", en: Revista Chilena de Derecho del Trabajo y de la Seguridad Social, vol. IV, $\mathrm{n}^{\circ} 7$, 2013, Santiago, Chile, pp. 25-41.

11 Fundación Sol. "Plan Nacional para salir de la Trampa del Mini Salario Mínimo" [en línea], <http://www.tutrabajovale.cl/ wp-content/uploads/2012/06/Ideas-Salario-M\%C3\%ADnimo-VFinal.pdf> [consulta 20 de julio de 2013]
} 
ción de los precios de los bienes que se pretendía proteger -quizá el caso paradigmático sea el de las quemas de café con precios protegidos en Brasil, a principios del siglo XX, para deshacerse del sobre-stock y forzar al alza los precios- ${ }^{12}$. Pero aun cuando no existiera ni un solo caso observado en el pasado del efecto contraproducente de los salarios-precios mínimos, la sola aplicación de las categorías de la acción humana nos lleva a la conclusión de que un alza de los salarios (precio) por sobre lo que el mercado determine, conduce ceteris paribus al desempleo (sobre-oferta).

Por eso, cuando se dice que se ha observado que "no existe evidencia empírica de carácter unívoco" sobre la relación entre un sueldo mínimo y desempleo; no significa que se ha logrado derogar las leyes económicas permanentes de los precios (nadie que alguna vez haya echado a volar unos aviones de papel sostendrá que ha derogado la ley de la gravedad). Esta falta de univocidad observada, se debe a que se ha usado un método equivocado: el método de la sistematización estadística de datos históricos (que como datos pasados, ya pasaron para siempre), que sólo es válido para comprender hechos pretéritos pero nunca para enunciar ni invalidar las leyes económicas. Los fenómenos de la realidad son complejos y se presentan como resultado de múltiples causas, y si no se separan cada una de ellas es imposible establecer las verdaderas vinculaciones entre una causa y un efecto dado ${ }^{13}$. (De hecho, cualquier persona que no esté cegada por el fanatismo, puede entender que ceteris paribus un alza del precio de un bien disminuirá su demanda, ¿qué fuerza mística provoca que los salarios no se rijan por esta ley?)

Lo que ocurre y ha ocurrido siempre es que detrás de los fenómenos sociales que se observan hay infinidad de causas involucradas, y tal como un alza de salarios por sobre la productividad marginal del trabajo desata una poderosa fuerza a favor del despido de los trabajadores marginales, ésta puede verse amenorgada o inclusive anulada por otras causas como un aumento de la masa monetaria que empuje los precios al alza, y, entonces, por un tiempo puede que se observe hasta un aumento de la contratación (también por una política de baja tasa de interés que empuje a la inversión en capital fijo intensivo en el uso de mano de obra; aumento del gasto público; subsidios a la contratación; etc.). En consecuencia, quien no sea capaz de reconocer la naturaleza de la acción humana no puede tampoco reconocer cuáles son los límites del análisis histórico-estadístico.

La prueba vergonzante de que los propios defensores del sueldo mínimo no creen en su postulado de que no existe vínculo entre el sueldo mínimo y el desempleo, está en que no son consecuentes con él, pues ¿qué impide que el salario mínimo se fije en tal cuantía que erradique de una vez cualquier atisbo de pobreza? No cabe duda de que la respuesta es que esto generaría un desempleo generalizado. Por otra parte, qué credibilidad puede merecer un planteamiento científico que desarrollado como constatación empírica (no existe evidencia de la relación entre salario mínimo y aumento del desempleo) es a renglón seguido obviado, pues se proponen subsidios a la demanda (contratación de trabajadores) tal como en cualquier otra vulgar fijación de precios mínimos:

\footnotetext{
12 Los ejemplos de destrucción de sobre stock son antiguos en la historia de la economía, Stuart Mill refirió el célebre caso de la antigua Dutch East Indian Company que "se veía obligada en ańos buenos a destruir una parte de la cosecha. Si hubiera tratado de vender toda su producción habría tenido quizá que forzar el mercado y reducir tanto su precio que la venta de un volumen mayor le hubiera rendido menos que la de una cantidad menor: al menos, tal parecía ser su punto de vista al destruir su sobrante". Citado por Robinson, E.A.G. Monopolio.-2a Ed.-. México: Fondo de Cultura Económica, 1950, p. 13.

13 "La noción vulgar de que los métodos seguros en asuntos políticos son los de la inducción baconiana -que el verdadero guía no es el razonamiento general, sino la experiencia específica-, se mencionará algún día entre las características más inequívocas de una pobre condición de las facultades especulativas de cualquier época en que se haya acreditado(...) Debe enviarse a aprender los rudimentos de alguna de las ciencias físicas más fáciles a todo aquel que use un argumento de esa clase. Semejantes razonadores ignoran el hecho de la pluralidad de causas en el caso especial que proporciona el ejemplo más seńalado de ello". StUART Mill, John. Lógica, X, 8. Citado por Robbins, Lionel. Naturaleza y Significación de la Ciencia Económica. -2a Ed.-Madrid, España: Fondo de Cultura Económica, 1951, p. 108, n 4.
} 
Jorge Martínez Rivera / Efectos y naturaleza del salario mínimo

"Se aplicará un subsidio temporal y diferenciado a las cotizaciones de los trabajadores asalariados de empresas de menor tamaño las cuales se dividen en 3 grupos: i) Con ventas anuales hasta 600 UF; ii) Entre 600 y 5.000 UF y iii) Entre 5.000 y 25.000 UF”.

"Para los jóvenes entre 18 y 25 años y mujeres jefas de hogar mayores de 25 años que pertenezcan al $40 \%$ de los hogares más pobres y que sean contratados por empresas que vendan menos de 25.000 UF al año, se les subsidiará las cotizaciones, en los montos y porcentajes que se indique cada año. Se asume como supuesto que cada año el número de jóvenes y mujeres de este segmento que encuentran un trabajo crece un 5\%"14.

Ser sorprendido en tal renuncio, sería la vergüenza de cualquier científico social, pero no para los defensores del sueldo mínimo, como se ve.

Decíamos arriba, que los subsidios son la forma utilizada desde siempre para aplacar los efectos de la sobre-oferta en cualquier clase de política de fijación de precios mínimos, se trate de café o trabajadores (lamentablemente -para los intervencionistas del mercado del trabajo-, a los trabajadores desempleados por sus políticas de precios mínimos no se les puede quemar como al café y así sus ensoñaciones tengan más chance de llevarse a cabo).

La exhibición formal, y en cuanto tal con un importante valor lógico y analítico, sobre los alcances de un alza del precio sobre la oferta y la demanda fue presentada definitivamente por Alfred Marshall en sus Principios de Economía ${ }^{15}$ (1890); nosotros seguiremos su diagramación y nomenclatura, en la figura 1, pero aplicada al mercado del trabajo, entendiendo por tal "aquel sector del mercado de los bienes de producción en el que se contrata el trabajo" ${ }^{16}$.

\section{Figura 1}

Efecto del sueldo mínimo en el mercado de trabajo

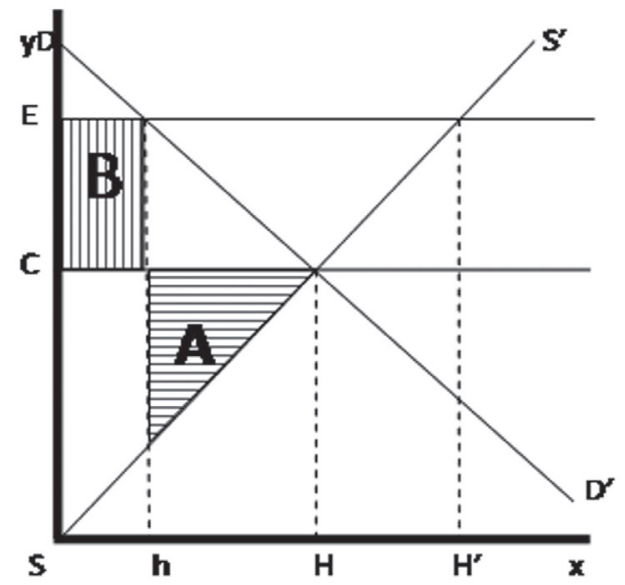

\footnotetext{
$14 \quad$ Ibid.

15 Marshall, Alfred. Principios de Economía. $-4^{\circ}$ Ed.-. Madrid, España: Aguilar, 1963, p. 386. En esta parte también es muy útil (aunque con leguaje matemático) la obra de Friedman, Milton. Teoría de los precios. Barcelona, Espańa: Altaya, 1997.

16 Mises, Ludwig, op. cit. (n. 4), p. 703.
} 
En el diagrama, el eje de las abscisas (x) representa la cantidad de trabajadores y el eje de las ordenadas (y) los salarios (precios). Suponemos que la curva de oferta SS' se intersecta con la de demanda DD' en el precio C, en ese punto se logra colocar $\mathrm{H}$ cantidad de trabajadores, es decir, a todos los trabajadores dispuestos a emplearse a ese precio. Supongamos, que una ley de sueldo mínimo obliga a que los salarios se ubiquen ahora en el punto $\mathrm{E}$. Al nuevo precio se demanda una cantidad menor de trabajadores representada por h en el eje de las abscisas, esto implica que la diferencia entre $\mathrm{H}$-h representa a aquellos trabajadores que se han quedado desempleados gracias a la ley de sueldo mínimo (desempleo que llamamos institucional pues ha sido creado por la ley). Junto con lo anterior, el nuevo precio E ha producido un aumento de la oferta de trabajadores hasta H', que tampoco conseguirá colocarse.

Resulta también interesante analizar lo que ocurre con el área destacada A, que representa lo que en términos marshallianos se llama "excedente del oferente" (en este caso de los trabajadores) que no se percibe más gracias a la fijación coactiva de los salarios, estas remuneraciones que se pagarían a precio no intervenido y que ya no se pagan, representan una riqueza perdida irrecuperable para los trabajadores de este mercado.

El área B ilustra la porción de recursos (excedente del demandante en términos del mismo Marshall) que se han transferido desde los demandantes (empleadores) hacia los trabajadores, pues, es claro que también gracias a la coacción hay trabajadores que se encuentran en una situación mejor que a precio de mercado no intervenido. Pero, esto sólo resulta posible mientras la ley siga impidiendo a los trabajadores (representados por el segmento $\mathrm{hH}^{\prime}$ ) emplearse. Entonces, todo el bienestar que se puede atribuir al salario mínimo tiene su exclusiva causa en que se permite que los trabajadores desempleados (excluidos por el desempleo institucional) sean sacrificados a favor de los empleados.

No puede dejar de considerarse que el exceso de oferta de trabajo creado por el sueldo mínimo (sea los que fueron despedidos o los que han sido atraídos al mercado por los mayores precios pagados) crea una poderosa fuerza hacia la baja de los salarios. Nosotros sabemos que ceteris paribus un aumento de oferta produce baja del precio. Así, el trabajador desempleado comenzará a buscar empleo en todas las empresas que en el mercado en cuestión existan, al encontrar las plazas ocupadas y no poder aumentar su productividad en el corto plazo, tratará de diferenciarse por precio y como no podrá ser contratado pues la ley lo prohíbe, se le condena al trabajador (y a quienes de él dependen) a la penuria del desempleo (o al trabajo informal), "y a los trabajadores actualmente empleados les puja inexorablemente sus salarios a la baja", y no hay legislación ni sofisma económico capaz de derogar esta realidad.

Un subsidio a los desempleados víctimas del salario mínimo, la creación de salarios mínimos diferenciados por grupos de trabajadores, los incentivos a la contratación para absorber el desempleo institucionalizado, son todas soluciones a un problema que jamás hubiera tenido lugar si se hubiera dejado funcionar al sistema de precios que vacía el mercado, coloca a todo el que quiera trabajar, y provoca una poderosa tendencia a la subida generalizada de los salarios. Sólo los ignorantes o los malvados pueden pretender reemplazar por sus propias arbitrariedades, fundadas en una irracional justicia social, el sistema de precios (salarios) de mercado.

Otra pieza fundamental de lo que venimos llamando supersticiones en torno al salario mínimo, es la que se refiere a que es necesario mantener un salario mínimo por las imperfecciones del mercado, específicamente, se habla de las tendencias "monopsónicas" que perjudicarían a los trabajadores ${ }^{17}$. Esto ha sido expuesto de la siguiente manera:

\footnotetext{
La noción de que los empleadores tienen poder para bajar salarios, aumentando sus beneficios a costa de los trabajadores, es
} 
"En "mercados monopsónicos", con escasez de demandantes de trabajo y en donde el empleador determina unilateralmente el salario de sus trabajadores que maximizará su tasa de ganancias, el efecto de un alza en el salario mínimo tiende a ser nulo o incluso positivo (alzas en el salario mínimo aumentaran la tasa de ocupación)" (sic) ${ }^{18}$.

También en think tanks respetables, Libertad y Desarrollo, encontramos presente el dislate de que el sueldo mínimo protege del monopsonio del empleador: "Dentro de los [aspectos positivos del salario mínimo] se pueden mencionar dos; el primero es evitar situaciones de abuso cuando existe algún grado de "poder monopsónico" del empleador"19.

Esta idea de que un supuesto monopsonio podría ser resuelto a través de una coacción legislativa (salario mínimo), adolece de graves problemas tanto desde la perspectiva de la teoría económica como de idoneidad de la herramienta jurídica elegida.

Se ha pretendido ver en el monopsonio la contrapartida del monopolio. Se cree que tal como el vendedor monopólico puede reducir la oferta para así obtener aumento de los precios y ganar una renta monopólica, burlando de ese modo la soberanía del consumidor, algo similar ocurriría con el comprador único de un bien o servicio, en este caso de trabajo. Sin embargo, las situaciones de ambos casos ofrecen importantes matices. En primer lugar, el vendedor que monopoliza algún bien o servicio no necesariamente reducirá la oferta y desatenderá la demanda, esto sólo ocurrirá si la ganancia monopólica es capaz de compensar la reducción de la demanda por el mayor precio. Además, cuando hay un único comprador (monopsonio) su situación no es distinta de la que se daría en cualquier otro caso de mayor concurrencia, pues nunca el comprador puede obtener "rentas monopsónicas" al estilo de las "rentas monopólicas" que obtiene el vendedor monopólico. Esto es así, porque si el comprador decide comprar menos para forzar el precio a la baja respecto al que pagaría en un mercado con más compradores, no obtiene de ello ninguna renta extraordinaria pues al mismo tiempo estará adquiriendo una menor cantidad de bienes y servicios, y si se trata de un factor productivo, lo único que consigue es reducir la producción y, por ende, sus propias ganancias. Como queda de manifiesto, nada hay en un supuesto monopolio de demanda que justifique, como herramienta jurídica eficaz, la fijación legal de precios mínimos coactivos para proteger la oferta.

Se dirá que la oferta de trabajo es inelástica y que el hambre acuciará a los trabajadores a emplearse sin importar lo bajos que sean los salarios que pague el empresario. Por lo que habrá explotación de esta debilidad del trabajador para apropiarse de la diferencia entre lo que hubiera correspondido al trabajador de acuerdo con el mercado y el salario menor pagado. Este razonamiento es falaz, ya que supone la inexistencia de competencia no de compradores sino de vendedores (mercado de bienes finales). Es la competencia en el mercado de bienes finales lo que impide a los empresarios quedarse con supuestas rentas monopsónicas sin traspasar sus economías a los precios de los bienes finales, por tanto, el empresario sólo se podría beneficiar en cuanto consumi-

antigua en la historia de las ideas económicas, ya Adam Smith en su célebre Riqueza de las Naciones decía: "Los patronos, al ser menos, pueden asociarse con más facilidad (...) Los patronos están siempre y en todo lugar en una especie de acuerdo, tácito pero constante y uniforme, para no elevar los salarios sobre la tasa que exista en cada momento. Violar este concierto es en todo lugar el acto más impopular, y expone al patrono que lo comete al reproche de vecinos y sus pares. Es verdad que rara vez oímos hablar de este acuerdo, porque es el estado de cosas usual (...) Los patronos entran a veces en uniones particulares para hundir los salarios por debajo de esa tasa”. Sмiтh, Adam. La Riqueza de las Naciones.-3º Ed.-. Madrid, España: Alianza Editorial, 2011, p. 111.

18 Fundación Sol, op. cit. (n. 11).

19 Libertad y Desarrollo. Reajuste del Salario Minimo: La Importancia de mantener la prudencia [en línea] <http://www.lyd.cl/ wp-content/files_mf/tp1066salariominimo.pdf> [consultado el 20 de julio de 2013]. 
dor pero no como rentista monopsónico. Para que los empresarios pudieran acordar restringir los salarios de esta manera tendrían que contar con los supuestos típicos de la actividad monopólica de oferta, por ejemplo, patentes, privilegios de propiedad intelectual, permisos administrativos, barreras de entrada u otra protección estatal; si no es así, debieran contar con el monopolio de algún factor productivo necesario en todas las ramas productivas que les asegurara que otros empresarios no pudieran ingresar a disputar aquellos trabajadores explotados. Comoquiera que no existe un factor productivo con esas características ni barrera de entrada universal al mercado (salvo en una economía socialista), el argumento de la renta monopsónica para justificar el salario mínimo es bastante ilusorio. En rigor, se trataría de un problema de monopolio de oferta y no, como equivocadamente se sostiene, de monopolio de demanda o "monopsonio" 20 . Y la solución al monopolio de oferta sólo puede ir por la vía de reducir las barreras institucionales a la competencia, pues tan pronto como nuevos empresarios perciben la posibilidad de lucro en el mercado libre y los confabulados se percataran de esta amenaza, se restablecería la tendencia a que se remunere de acuerdo con la productividad marginal.

Por otra parte, el ilusorio monopolio de demanda patronal presume que los trabajadores carecen por completo de reservas y que no están dispuestos a esperar por mejores ofertas de trabajo, lo que es contrario a la realidad (una parte del desempleo es voluntario, de trabajadores que buscan mejores posibilidades laborales); sólo en un esquema socialista es posible que los trabajadores estén cautivos de un único empleador, del tirano de turno. También presume que el empresario tiene la posibilidad de diferir a discreción la contratación hasta conseguir vencer la resistencia de los trabajadores a los bajos salarios, lo que es falso. Ningún beneficio obtiene el empresario de mantener detenido o funcionando de forma parcial su capacidad productiva, sobre lo más seguro es que tenga apremiantes obligaciones con los dueños del capital. En términos relativos la posición del empresario en el capitalismo es mucho más apremiante que la del trabajador, el empresario es quien más tiene que perder si no se allana a actuar conforme con la estructura del mercado. En consecuencia, es falso que exista una tendencia generalizada (ni marginal) al monopsonio de empleadores, que justifique una ley de salario mínimo. Finalmente, si lo vemos con detención, la teoría del monopsonio de empleadores es sólo una forma más sofisticada de presentar un error más antiguo (teoría de la explotación), que predica que el empresario se apropia de diferencias que corresponderían al trabajador (en este caso una ilusoria "renta monopsónica"), imponiendo un salario más bajo que el aporte del trabajador.

A fin de cuentas, toda la mitología del monopsonio patronal se basa en la ignorancia de que el factor trabajo siempre es el más escaso (respecto a los demás factores), y que la posibilidad de explotar la tierra y el capital disponible pasa por contar con el trabajo necesario.

No obstante lo dicho, hagamos un ejercicio de imaginación, supongamos, contra toda la lógica y la teoría económica, que el mercado de trabajo no funciona, y existe tal cosa como un monopolio generalizado de demanda de trabajo capaz de producir una específica "renta monopsónica”. ¿Qué papel jugaría aquí el sueldo mínimo? Considerando que la contratación de más trabajadores en el supuesto mundo monopsónico seguirá dependiendo del comportamiento del monopsonista respecto de los precios, un salario mínimo sirve de poco si no va acompañado de la obligación expresa de contratar un número determinado de trabajadores (hasta el punto que se anule la renta monopsónica) al precio fijado y de no despedirlos; la ley también debería señalar que esto debe ocurrir inmediatamente pues de esa forma se salva el problema de la postergación (con miras a vencer su resistencia a los bajos salarios) en el empleo de la que han sido víctimas

20 Mises, Ludwig, op. cit. (n. 4), pp. 460-462, 703-706. 
los trabajadores. Entonces, la única forma coherente con las premisas planteadas de defender el salario mínimo como solución al imaginario monopsonio patronal no es tratándolo -como se ha hecho hasta ahora- como una forma de contratación dirigida (contrato con un cierto contenido mínimo indisponible), eso es insuficiente si no va unido a una obligación del empresario en orden a la contratación forzosa de trabajadores, pues, sólo así se conseguiría efectivamente el fin propuesto por los intervencionistas que vinculan el salario mínimo con la supresión de las ganancias monopsónicas. Ahora, esta necesaria consecuencia debiera parecer excesiva hasta a los propios adalides del salario mínimo (que tengan algún respeto por el Estado de Derecho), pues desde el intervencionismo de los precios hemos pasado al control de la producción; jurídicamente, una política coherente de salarios mínimos, implica laminar el derecho a la libertad de empresa, de propiedad privada, y entrar de lleno a un régimen de dirigismo estatal de la actividad económica ${ }^{21}$.

Sin llegar al extremo descrito, ¿qué es jurídicamente hablando el salario mínimo? Se trata de una simple prohibición de contratar, que convierte en ilícito el pacto de salario que en un mercado no intervenido sería lícito convenir entre las partes. Funciona como una conculcación a la libertad de trabajo del trabajador y a la libertad de empresa del empleador. También su efecto indirecto es la creación de un estatuto para los trabajadores empleados (que logran beneficiarse del salario impuesto) y los que quedan desempleados por su causa: la ley es apartada de su función de otorgar igual protección a todos los ciudadanos en el ejercicio de sus derechos y sacrifica a unos trabajadores en beneficio de otros ${ }^{22}$, es fuente de desigualdad.

\section{BIBLIOGRAFÍA}

Ávila, Alamiro de. Derecho Romano. -2 Ed.-. Santiago, Chile: Editorial Jurídica de Chile, 2000.

Bates Clark, John. The Distribution of Wealth. Londres, Inglaterra: The MacMillan Company, 1938.

Gamonal, Sergio. Derecho Colectivo del Trabajo. Santiago, Chile: LegalPublishing, 2008.

Libertad y Desarrollo. Reajuste del Salario Minimo: La Importancia de mantener la prudencia [en línea] $<$ http:// www.lyd.cl/wp-content/files mf/tp1066salariominimo.pdf> [consultado el 20 de julio de 2013].

Marshall, Alfred. Principios de Economía. $-4^{\circ}$ Ed.-. Madrid, España: Aguilar, 1963 Friedman, Milton. Teoría de los precios. Barcelona, España: Altaya, 1997.

Martínez, Jorge. "Teoría Pura de los salarios", en: Revista Chilena de Derecho del Trabajo y de la Seguridad Social, vol. IV, n 7, 2013, Santiago, Chile, pp. 25-41.

Marx, Karl. El Capital. Vol. I. México: Fondo de Cultura Económica, 2012.

Mises, Ludwig. La Acción Humana. Tratado de Economía. - - E Ed.-. Madrid, España: Unión Editorial, 2007.

Robinson, E.A.G. Monopolio.-2a Edición-. México: Fondo de Cultura Económica, 1950.

RöpкE, Wilhelm. La Teoría de la Economía. Madrid, España: Unión Editorial, 2007.

Sмith, Adam. La Riqueza de las Naciones.-3 Ed.-. Madrid, España: Alianza Editorial, 2011.

21 Tal fue la política económica de Hitler en el III Reich, donde mantuvo la apariencia de propiedad privada sobre los medios de producción, pero correspondía al Estado decidir sobre cada aspecto de la producción (precios, salarios, tipos de cambio, regulación del consumo, fiscalización del capital y de las inversiones). Röpke, Wilhelm. La Teoría de la Economía. Madrid, Espańa: Unión Editorial, 2007, p 114.

22 Así las cosas, no cabe duda de que una acción más intelectualmente coherente, de los defensores del salario mínimo, sería intentar convencernos de que el desempleo, los bajos salarios y la desigualdad son fines sociales valiosos; en tal caso habría que concederles la razón, en el sentido de que el sueldo mínimo es un excelente medio para conseguirlos. 
Stuart Mill, John. Lógica, X, 8. Citado por Robbins, Lionel. Naturaleza y Significación de la Ciencia Económica. -2a Ed.-Madrid, España: Fondo de Cultura Económica, 1951.

Villee, Claude. Biología. -7º Ed.-. México: Mc Graw Hill, 1988. 